\title{
Physical activity and inactivity in primary and secondary school boys' and girls' daily program
}

\author{
Romana Hubáčková ${ }^{1, *}$, Dorota Groffik², Lukasz Skrzypnik², and Karel Frömel ${ }^{1}$ \\ ${ }^{\text {I}}$ Faculty of Physical Culture, Palacký University Olomouc, Olomouc, Czech Republic; and ${ }^{2}$ The Jerzy Kukuczka Academy \\ of Physical Education in Katowice, Katowice, Poland
}

Copyright: () 2016 R. Hubáčková et al. This is an open access article licensed under the Creative Commons Attribution License (http://creativecommons.org/licenses/by/4.0/).

\begin{abstract}
Background: Children's and youth education is becoming more and more demanding. In conjunction with development of information technology, this fact negatively affects lifestyle of children and youth. Apart from families, schools should play a crucial role in healthy lifestyle promotion in children and youth. Objective: The present study aimed to assess differences in physical activity (PA) and physical inactivity (PI) among primary and secondary school boys and girls in specific segments of a school day. Methods: The research was conducted between 2010 and 2014 at 15 secondary schools (SS) and 9 primary schools (PS) in the Silesia-Katowice region in Poland. In total, 86 boys and 71 girls at PS and 125 boys and 113 girls at SS took part in the research. We recorded 587 school days, in total. The ActiTrainer accelerometer was used for PA and PI monitoring. Results: PS boys and girls were more physically active than SS boys and girls. Before school, we observed SS boys to have higher energy expenditure than PS boys $(p<.001)$ and also than SS girls $(p<.001)$. During the school time, $73 \%$ of PS boys $(40 \%$ at SS) and $58 \%$ of PS girls (42\% at SS) met the recommendation of 500 steps/hour. Within the entire school day monitoring, $44 \%$ of PS boys (29\% at SS) and 41\% of PS girls (34\% at SS) met the recommended 11,000 steps/day. Conclusions: The results of our study confirmed the facts that PS boys and girls are more physically active than SS boys and girls and, furthermore, that boys are more physically active than girls at both types of schools.
\end{abstract}

Keywords: accelerometer, monitoring, heart rate, school day segments

\section{Introduction}

In socioeconomically developed countries, people's life habits tend to change (Brodersen, Steptoe, Boniface, \& Wardle, 2007), standards of living rise (Kim \& Lee, 2016) and new opportunities for people within the society occur (Nader, Bradley, Houts, McRitchie, \& O'Brien, 2008). Children spend too much time in front of the PC or TV and the content of their leisure becomes very limited (Hamř́k, Kalman, Bobáková, \& Sigmund, 2012; Howie, Campbell, \& Straker, 2016; Pastucha et al., 2010). Yet, for instance, walking is one of very easy-to-do kinds of health-enhancing physical activity (PA) (Collins \& Fulton, 2015; Faulkner, Buliung, Flora, \& Fusco, 2009; Haskell, Blair, \& Bouchard, 2007). Because of these changes we can observe

\footnotetext{
* Address for correspondence: Romana Hubáčková, Institute of Active Lifestyle, Faculty of Physical Culture, Palacký University Olomouc, třída Míru 117, 77111 Olomouc, Czech Republic. E-mail: romanasnoblova@seznam.cz
}

decrease of the PA level (Harrison, van Sluijs, Corder, \& Jones, 2016), physical fitness, unbalanced energy intake and expenditure (Horsch et al., 2015), which lead to rise in prevalence of overweight and obese younger school-aged children (Daniels et al., 2005).

These issues act as an impulse to seek and verify programs for children (Mei et al., 2016) that would promote PA and reduce risk of overweight or obesity (Ward, Saunders, \& Pate, 2007). Such programs include, among others, active spending of recess time at schools (Hood, Colabianchi, Terry-McElrath, O’Malley, \& Johnston, 2014; Morton et al., 2016) and active transport to and from school (Babey, Hastert, Huang, \& Brown, 2009), which both have a significant potential to increase PA among children and youth (Abbott, McDonald, Nambiar, \& Davies, 2009; Faulkner et al., 2009; Martin, Lee, \& Lowry, 2007).

School days play the crucial role in weekly PA, which has been shown both abroad (Duncan, Duncan, \& Schofield, 2008; Rowlands, Pilgrim, \& Eston, 2008; Treuth et al., 2007) and in Polish and Czech conditions 
(Groffik, Sigmund, Frömel, Chmelík, \& Nováková Lokvencová, 2012; Nováková Lokvencová, Frömel, Chmelík, Groffik, \& Bebčáková, 2011; Vašičková, Pelclová, Frömel, Chmelík, \& Pelcl, 2008). Despite the daily recommendation of 11,000 steps/day (TudorLocke et al., 2011) this threshold is not met by $46 \%$ of 16 year old boys and $43 \%$ of 16 year old girls regardless of the fact that they achieve 500 steps/hour on average during school time (Frömel, Svozil, Chmelík, Jakubec, \& Groffik, 2016). Those who had a less stimulating school regime in terms of physical activity fail to meet this daily recommendation even to further extent (in total $75 \%$ of boys and $68 \%$ of girls). According to the study by Frömel, Kudláček, Groffik, Chmelík, and Jakubec (2016), sedentary behaviour on school days is not compensated for during PA at weekends.

The present study, therefore, aimed to assess differences in physical activity and inactivity among primary and secondary school boys and girls in specific segments of a school day, which should bring new findings allowing development of more efficient lifestyle interventions in these age categories.

\section{Methods}

\section{Sample}

The research was conducted between 2010 and 2014 at 9 primary (PS) and 15 secondary schools (SS) in the Silesia-Katowice region in Poland. Research was carried out in the periods of September-October and April-May, which are the most suitable months for conducting survey in terms of the school year and season. Neither major changes in school schedule nor weather extremes occurred during the study period. Because of organisational demands of research in natural school conditions, we selected only schools, where student teaching practice takes place regularly. In case there were more than two classes in a given grade, the school management selected those classes that had the most typical weekly program in the research period. The management of selected schools and respective teachers agreed with the survey. A week before the survey, all the participants were informed about the research and its aims. In total, 395 participants were involved in the research: 86 boys and 71 girls at PS and 125 boys and 113 girls at SS (Table 1). All the parents of PS children gave consent for their children's participation in the study. The research design and the associated documentation were approved by the Ethics Committee of the Faculty of Physical Culture, Palacký University Olomouc.

\section{Procedure}

For PA and physical inactivity (PI) monitoring we used the ActiTrainer (Actigraph, Pensacola, FL, USA), which monitors PA (counts) and heart rate (HR - beats per minute). At PS, parents were informed about the research, its procedure and purpose at first and all of them agreed to help their children complete the PA records and check monitoring devices. The same research team provided participants with instructions regarding the study throughout the research period. The participants were informed about the way to monitor PA, wear and remove devices, monitor HR, and also to fill the recording sheets in (course of the day, recording the time of particular day segments and type of PA). The data on age, height and weight were obtained during initial meeting with participants. Proper function of HR monitoring was checked after participants' arrival in school using the Polar S610 Heart Rate Monitor (Polar Electro Oy, Finland). The participants wore the accelerometer on two consecutive school days, provided one of these days included a physical education lesson (PEL). Individualised feedback on basic monitoring results (load intensity in the MET and HR zones, energy expenditure, HR records and step counts) were given to participants three weeks after the end of the research.

\section{Monitoring and data processing}

The participants recorded (at PS with assistance of teachers and parents) predetermined time points in the course of the day: before school, at school according

Table 1

Sample characteristics

\begin{tabular}{|c|c|c|c|c|c|c|c|c|c|}
\hline \multirow[b]{2}{*}{ Gender/school } & \multirow[b]{2}{*}{$n$} & \multicolumn{2}{|c|}{ Age (years) } & \multicolumn{2}{|c|}{ Weight (kg) } & \multicolumn{2}{|c|}{ Height (cm) } & \multicolumn{2}{|c|}{ BMI $\left(\mathrm{kg} / \mathrm{m}^{2}\right)$} \\
\hline & & $M$ & $S D$ & $M$ & $S D$ & $M$ & $S D$ & $M$ & $S D$ \\
\hline Boys PS & 86 & 9.45 & 0.39 & 34.64 & 7.23 & 135.41 & 5.74 & 18.79 & 3.07 \\
\hline Girls PS & 125 & 9.43 & 0.38 & 34.14 & 10.19 & 135.64 & 6.59 & 18.30 & 3.79 \\
\hline Boys SS & 71 & 16.19 & 0.72 & 67.42 & 11.03 & 176.20 & 7.14 & 21.65 & 2.94 \\
\hline Girls SS & 113 & 16.49 & 0.80 & 57.75 & 7.88 & 166.11 & 5.76 & 20.89 & 2.34 \\
\hline
\end{tabular}

Note. $\quad n=$ number of participants; $\mathrm{BMI}=$ body mass index; $\mathrm{PS}=$ primary school; $\mathrm{SS}=$ secondary school. 
to their schedule of lessons and recesses, after school and aggregate data for the entire day. Apart from time characteristics, the participants also indicated type of physical activity and inactivity (sitting/lying down, TV, PC, at school, commuting, culture/spectatorship) in order to obtain more specific data to complement the data from objective PA monitoring. The inherent software program was used to process the data (15 sec recording). The software program processed data on duration of PA in specific intensity zones and duration of PI in minutes in line with the established methodology (Frömel, Svozil, et al., 2016; Svozil et al., 2015). To compare data in particular day segments, we transformed all the values to one hour - active energy expenditure (kcal/kg/hour), step count (steps/hour), PA intensity in the $\geq 60 \% \mathrm{HRmax}$ zone (min/hour) and PI duration (min/hour).

In the analyses we used only the data of those participants who wore the monitoring devices for at least 15 minutes before school, at least 180 minutes at school (excluding PELs), at least 120 minutes after school and in total for at least 600 and at most 1,080 minutes, respectively, throughout the day. Due to incomplete all day PA records, 99 participants were excluded from the study and 104 monitoring days were excluded because of failure to comply with requirements regarding the daily segment records. Overall, 587 school days were included in the study. The excluded daily records were homogeneously distributed with regard to gender at both PS and SS, whereas the reduction ranged between $23 \%$ and $28 \%$ on average. Also inclusion of participants with only one valid PA monitoring day was proportional within the study sample.

\section{Data analysis}

The Kruskal-Wallis test and contingency tables with Pearson's $\chi^{2}$ were used to analyse the data in the Statistica program (Version 12; StatSoft, Tulsa, OK, USA). The $\eta^{2}$ effect size coefficient was set as small
$.01 \leq \eta^{2}<.06$; medium $.06 \leq \eta^{2}<.14$; and large $\eta^{2} \geq .14$ and the $w$ coefficient as low $.1 \leq w<.3$; medium $.3 \leq w<.5$; and high $\geq .5$ (Cohen, 1988; Sheskin, 2007).

\section{Results}

\section{PA before school}

Before school, we observed SS boys to have higher energy expenditure than PS boys $(p<.001)$ and also than SS girls $(p<.001)$. SS girls had still higher energy expenditure than PS girls $(p=.025)$ (Table 2). Similar differences were found in the daily step counts. The SS boys reached a mean of 1,760 steps/hour before school, which is significantly more than PS boys who had a mean of 1,389 steps/hour $(p=.003)$ and SS girls 1,331 steps/hour $(p=.007)$ in the same day segment (Table 3). Lower PA in SS girls was also accompanied by the level of PI. The SS girls spent more time being physically inactive than SS boys $(p=.004)$ and PS girls $(p<.001)$ (Table 4).

\section{PA at school}

The PS boys and girls showed higher energy expenditure than SS boys and girls $(p<.001$ and $p=.004$, respectively) (Table 2). The same differences between these groups were observed also in step counts at school. We found a significantly higher step count per hour in PS boys than PS girls during school $(p=.020)$ (Table 3). At school we observed a longer duration of PI (min/hour) in SS boys than in PS boys $(p<.001)$, in SS girls than in PS girls $(p<.001)$ and also in PS girls than in PS boys ( $p=.004)$ (Table 4$)$.

Higher PA in boys was confirmed also by means of heart rate $(\geq 60 \%$ HRmax) at the moderate-to-vigorous PA (MVPA) intensity during recesses (min/hour). Differences in MVPA, however, were insignificant between boys and girls at the PS $(p=.771)$ and SS $(p=.125)$,

Table 2

Energy expenditure (kcal/kg/hour) in primary and secondary school boys and girls in specific school day segments

\begin{tabular}{|c|c|c|c|c|c|c|c|c|c|c|c|}
\hline \multirow[b]{3}{*}{ School day } & \multicolumn{4}{|c|}{ Boys } & \multicolumn{4}{|c|}{ Girls } & \multirow[b]{3}{*}{$H$} & \multirow[b]{3}{*}{$p$} & \multirow[b]{3}{*}{$\eta^{2}$} \\
\hline & \multicolumn{2}{|c|}{ PS $(n=133)$} & \multicolumn{2}{|c|}{$\mathrm{SS}(n=102)$} & \multicolumn{2}{|c|}{ PS $(n=186)$} & \multicolumn{2}{|c|}{$\mathrm{SS}(n=166)$} & & & \\
\hline & $M d n$ & $I Q R$ & $M d n$ & $I Q R$ & $M d n$ & $I Q R$ & $M d n$ & $I Q R$ & & & \\
\hline Before school & 0.68 & 0.46 & 1.04 & 0.86 & 0.57 & 0.42 & 0.65 & 0.61 & $56.68^{\mathrm{a}, \mathrm{b}, \mathrm{d}}$ & $<.001$ & $.14 * * *$ \\
\hline At school & 0.50 & 0.38 & 0.26 & 0.33 & 0.41 & 0.32 & 0.38 & 0.32 & $46.31^{\mathrm{a}, \mathrm{b}}$ & $<.001$ & $.12 * *$ \\
\hline After school & 0.58 & 0.51 & 0.46 & 0.37 & 0.62 & 0.46 & 0.49 & 0.43 & $13.83^{\mathrm{b}}$ & .003 & $.04 *$ \\
\hline All day & 0.60 & 0.37 & 0.47 & 0.25 & 0.55 & 0.32 & 0.45 & 0.25 & $29.52^{\mathrm{a}, \mathrm{b}}$ & $<.001$ & $.07 * *$ \\
\hline
\end{tabular}

Note. $\quad$ PS = primary school; $\mathrm{SS}=$ secondary school; $n=$ number of monitored days; $H=$ Kruskal-Wallis test; $\eta^{2}=$ coefficient effect size. "small effect size; ${ }^{* *}$ medium effect size; ${ }^{* *}$ large effect size. ${ }^{a}$ significant difference between boys PS and boys SS; ${ }^{\text {bignificant difference }}$ between girls PS and girls SS; ${ }^{c}$ significant difference between boys PS and girls PS; ${ }^{d}$ significant difference between boys SS and girls SS. 
Table 3

Step counts (steps/hour) in primary and secondary school boys and girls in specific school day segments

\begin{tabular}{|c|c|c|c|c|c|c|c|c|c|c|c|}
\hline \multirow[b]{3}{*}{ School day } & \multicolumn{4}{|c|}{ Boys } & \multicolumn{4}{|c|}{ Girls } & \multirow[b]{3}{*}{$H$} & \multirow[b]{3}{*}{$p$} & \multirow[b]{3}{*}{$\eta^{2}$} \\
\hline & \multicolumn{2}{|c|}{ PS $(n=133)$} & \multicolumn{2}{|c|}{$\mathrm{SS}(n=102)$} & \multicolumn{2}{|c|}{ PS $(n=186)$} & \multicolumn{2}{|c|}{ SS $(n=166)$} & & & \\
\hline & $M$ & $S D$ & $M$ & $S D$ & $M$ & $S D$ & $M$ & $S D$ & & & \\
\hline Before school & 1,389 & 1,006 & 1,760 & 1,129 & 1,270 & 842 & 1,331 & 910 & $19.95^{\mathrm{a}, \mathrm{d}}$ & $<.001$ & $.05^{*}$ \\
\hline At school & 763 & 394 & 484 & 341 & 614 & 300 & 554 & 307 & $50.81^{\mathrm{a}, \mathrm{b}, \mathrm{c}}$ & $<.001$ & $.13^{* *}$ \\
\hline After school & 934 & 498 & 703 & 415 & 960 & 400 & 851 & 531 & $21.19^{\mathrm{b}}$ & $<.001$ & $.05^{*}$ \\
\hline All day & 891 & 322 & 673 & 253 & 862 & 263 & 733 & 289 & $40.88^{\mathrm{a}, \mathrm{b}}$ & $<.001$ & $.10^{* *}$ \\
\hline
\end{tabular}

Note. $\quad$ PS = primary school; $\mathrm{SS}=$ secondary school; $n=$ number of monitored days; $H=$ Kruskal-Wallis test; $\eta^{2}=$ coefficient effect size. "small effect size; ** medium effect size; ${ }^{* * *}$ large effect size. asignificant difference between boys PS and boys SS; bsignificant difference between girls PS and girls SS; ${ }^{`}$ significant difference between boys PS and girls PS; ${ }^{\circledR}$ significant difference between boys SS and girls SS.

Table 4

Duration of physical inactivity (min/hour) in primary and secondary school boys and girls in specific school day segments

\begin{tabular}{|c|c|c|c|c|c|c|c|c|c|c|c|}
\hline \multirow[b]{3}{*}{ School day } & \multicolumn{4}{|c|}{ Boys } & \multicolumn{4}{|c|}{ Girls } & \multirow[b]{3}{*}{$H$} & \multirow[b]{3}{*}{$p$} & \multirow[b]{3}{*}{$\eta^{2}$} \\
\hline & \multicolumn{2}{|c|}{ PS $(n=133)$} & \multicolumn{2}{|c|}{$\mathrm{SS}(n=102)$} & \multicolumn{2}{|c|}{ PS $(n=186)$} & \multicolumn{2}{|c|}{$\mathrm{SS}(n=166)$} & & & \\
\hline & $M d n$ & $I Q R$ & $M d n$ & $I Q R$ & $M d n$ & $I Q R$ & $M d n$ & $I Q R$ & & & \\
\hline Before school & 19.80 & 15.50 & 21.43 & 14.63 & 22.41 & 13.03 & 27.50 & 12.30 & $24.90^{\mathrm{b}, \mathrm{d}}$ & $<.001$ & $.06 * *$ \\
\hline At school & 27.56 & 8.63 & 39.45 & 11.46 & 30.68 & 8.62 & 40.91 & 9.39 & $241.70^{\mathrm{a}, \mathrm{b}, \mathrm{c}}$ & $<.001$ & $.61 * * *$ \\
\hline After school & 25.18 & 11.83 & 38.84 & 11.24 & 24.17 & 9.44 & 36.97 & 9.42 & $233.59^{\mathrm{a}, \mathrm{b}}$ & $<.001$ & $.59 * * *$ \\
\hline All day & 26.04 & 8.37 & 38.37 & 7.56 & 25.64 & 6.61 & 38.36 & 6.50 & $300.32^{\mathrm{a}, \mathrm{b}}$ & $<.001$ & $.76 * * *$ \\
\hline
\end{tabular}

Note. $\quad$ PS = primary school; $\mathrm{SS}=$ secondary school; $n=$ number of monitored days; $H=$ Kruskal-Wallis test $; \eta^{2}=$ coefficient effect size.

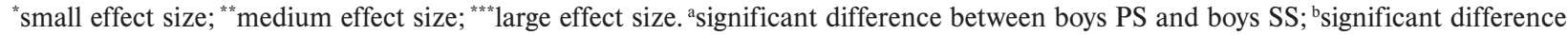
between girls PS and girls SS; ${ }^{c}$ significant difference between boys PS and girls PS; ${ }^{\mathrm{d}}$ significant difference between boys SS and girls SS.

respectively (Figure 1). Differences between PS and SS were not taken into consideration.

\section{PA after school}

We found that PS girls had higher energy expenditure in the time after school than SS girls $(p=.008)$ (Table 2). Likewise, we observed a significantly higher step count in PS girls compared with SS girls $(p=.006)$ (Table 3). Longer duration of PI was found in SS girls compared with PS girls $(p<.001)$, as well as in SS boys compared with PS boys $(p<.001)$ (Table 4$)$.

\section{All-day PA}

The gender differences and differences between school types, which were observed in specific day segments, were found in the all-day monitoring as well. There was a significant difference showing higher energy expenditure $(p<.001)$, as well as daily step count $(p<.001)$ in PS girls than in SS girls. Similarly, PS boys had higher all-day energy expenditure $(p=.014)$ and daily step count ( $p<.001$ ) than SS boys (Tables 2 and 3). SS boys and girls spent significantly more time being physically inactive than PS boys and girls, respectively $(p<.001)$ (Table 4).
During the school time, $73 \%$ of PS boys, $40 \%$ of SS boys, $58 \%$ of PS girls and $42 \%$ of SS girls met the recommendation of 500 steps/hour (Figure 2). The differences were significant between both types of schools $\left(\chi^{2}=38.52, p<.001, w=.256\right)$ in boys $(p<.001)$ and girls $(p=.002)$ and also between PS boys and girls $(p=.006)$.

Regarding the entire school day monitoring, $44 \%$ of PS boys, $29 \%$ of SS boys, $41 \%$ of PS girls and $34 \%$ of SS girls met the recommended 11,000 steps/day (Figure 2). From a daily step count perspective, PS boys had higher number of steps than SS boys $\left(\chi^{2}=4.97\right.$, $p=.026, w=.145)$.

\section{Discussion}

The important finding of the present study is that also in the Polish environment SS boys are more physically active in the period before school than PS boys and the same applies to girls with regard to active energy expenditure. These results are in line with findings of other authors, who claim that older children and youth use means of active transport to get to school more often 


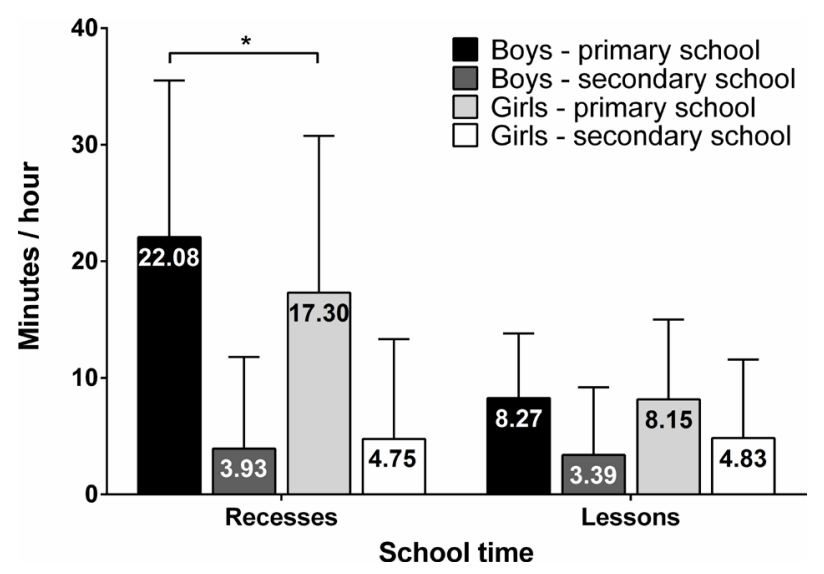

Figure 1. Time spent at the moderate-to-vigorous physical activity intensity ( $\geq 60 \%$ HRmax) during recesses and school time (min/hour) in primary and secondary school boys and girls (*significant difference between groups $p<.05$; differences between primary and secondary schools were not taken into consideration).

than their younger counterparts (Merom, Tudor-Locke, Bauman, \& Rissel, 2006). On the other hand, some authors contradict it (Schofield, Schofield, \& Mummery, 2005; Spallek, Tuner, Spinks, Bain, \& McClure, 2006). It is interesting, that before-school duration of PI does not correspond with duration of PA. Longer times of commuting to school, care about their appearance in girls and preparation before school lessons begin are perhaps the key factors of this disproportion.

During school time, as expected, PS pupils had higher energy expenditure, as well as step count, than SS students. Statistically significantly higher step count per hour was moreover observed in PS boys than PS girls during school. Duration of PI during school time corresponds with these results. Our findings also showed longer duration of PI (min/hour) among SS students than PS pupils. Moreover, PS girls spend more time being inactive, compared with PS boys. An important factor affecting the school-based PA and sedentary behaviour lies, apart from PELs, also in activities done during recesses. We found that PS boys spend $22.1 \mathrm{~min} /$ hour (girls $17.3 \mathrm{~min} /$ hour) in the MVPA zone during recesses, which represents $37 \%$ of the overall time of recesses (in girls it was 29\%). This is markedly more than Nettlefold et al. (2011) reported - 28\% of MVPA of the overall time of recesses in 8-11 year old boys and $20 \%$ in girls of the same age. Pupils' PA during recesses depends also on duration of recesses. The longer the recess is, the higher the odds for more PA during them (Verstraete, Cardon, De Clerq, \& Bourdeaudhuij, 2006). Spatial (Harrison et al., 2016) and material conditions play a role of similar importance (Loucaides, Jago, \& Charalambous, 2009). The PA

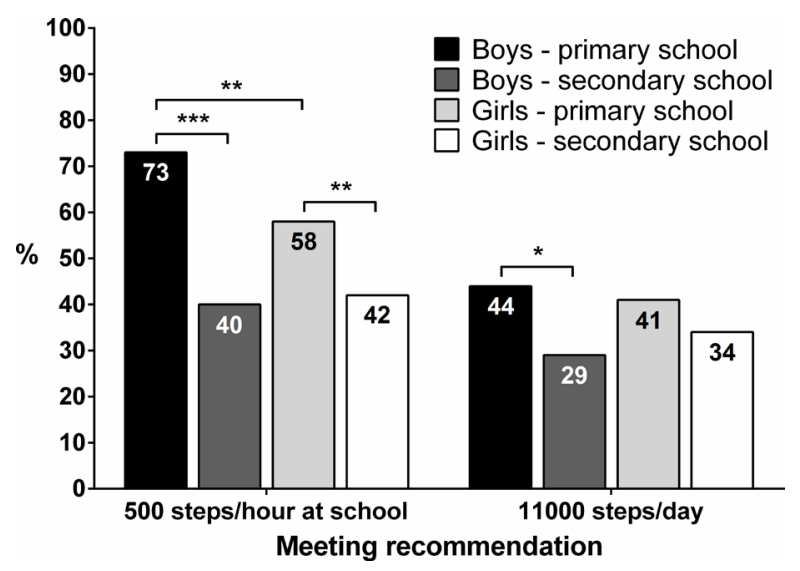

Figure 2. Rates of primary and secondary school boys and girls who met the recommendations of schoolbased step count (500 steps/hour) and daily step count (11,000 steps/day) (significant difference between groups $* p<.05, * * p<.01, * * * p<.001)$.

done during recesses might yield impact on health similar as PEL (Frömel, Stelzer, Groffik, \& Ernest, 2008). However, at SS it has been shown that longer aggregate time of recesses during a school program contributes to increase in PA volume regardless of gender, it cannot substitute PEL though (Frömel, Svozil, et al., 2016). This probably applies to PS, as well.

In after-school time, PS girls were more physically active than SS girls. The same applies to difference in PI between PS and SS boys. The usage of after-school leisure time for PA is possibly influenced by demands for schoolwork, which are higher at SS and thus more time-consuming than schoolwork at PS. Alternatively, it may be that SS students have more extensive opportunities for spending their leisure by non-PA activities. In general, amount of extracurricular activities drops down during adolescence (Jago, Anderson, Baranowski, \& Watson, 2005; Nováková Lokvencová et al., 2011; Verstraete et al., 2006). This decrease is more apparent in girls, as over a third of them quit doing sport activities on a regular basis in this developmental period (Pastucha, Filipčíková, Bezdičková, Blažková, \& Hyjánek, 2011). But Sigmundová, El Ansari, Sigmund, and Frömel (2011) found, that boys spend more time in front of PC than girls and, therefore, are less physically active during this day segment compared with girls.

The fact that more than half of PS pupils and two thirds of SS students do not meet the 11,000 steps/day recommendations is very alarming, although we know that PA level of children and youth decreases with increasing age (Pearson, Atkin, Biddle, Gorely, \& Edwardson, 2009; Tudor-Locke, McClain, Hart, Sisson, \& Washington, 2009) and that pre-schoolers are 
more physically active than adolescents and young adults both on school days and at weekends (TudorLocke et al., 2009). This situation is alarming especially because decrease in boys' and girls' PA contributes to increase of their body fat percentage and negatively affects efforts to maintain and promote children's health (Meriwether, Lobelo, \& Pate, 2008; Sigmund, Lokvencová, Sigmundová, Turoňová, \& Frömel, 2008; Sigmund, Sigmundová, \& El Ansari, 2009). In spite of these negative findings, it is clear that school program at PS is more favourable for physically active lifestyle than school program at SS.

In summary, the results of our study confirm that 9-10 years old boys and girls at PS are more physically active on school days than 15-17 years old boys and girls at SS, which is in line with a vast majority of similar studies (Morton et al., 2016; Pearson et al., 2009; Tudor-Locke et al., 2009).

\section{Strengths and limitations}

Due to organisational demands of the research in natural school conditions we did not monitor PA at PS on Mondays. Also at SS other days of week than Monday prevailed. Another limitation was that monitoring could not have been carried out concurrently at both types of schools and during a shorter monitoring period. The main strength of the study was an objective all-day monitoring of PA and HR and furthermore comparison of PA composition on particular school days in natural PS and SS conditions.

\section{Conclusions}

Secondary school students, especially boys, had significantly higher physical activity in the period before school than primary school pupils. During school time, as expected, primary school pupils had higher energy expenditure, as well as step count, than secondary school students. Duration of physical inactivity during school time corresponds with these results. Our findings showed longer duration of physical inactivity among secondary school students than primary school pupils. In the after-school time, primary school girls were more physically active than secondary school girls. The fact that more than half of primary school pupils and two thirds of secondary school students do not meet the 11,000 steps/day recommendations is very alarming. The results of our study confirmed the facts that had already been known, i.e. that primary school boys and girls are more physically active than secondary school boys and girls and, furthermore, that boys are more physically active than girls at both types of schools.

\section{Acknowledgment}

The research was supported by the Czech Science Foundation - research project "Objectification of comprehensive monitoring of school mental and physical strain in adolescents in the context of physical and mental condition" (No. 13-32935S).

\section{Conflict of interest}

There were no conflicts of interest.

\section{References}

Abbott, R. A., McDonald, D., Nambiar, S., \& Davies, P. S. W. (2009). The association between walking to school, daily step counts and meeting step targets in 5- to 17-yearold Australian children. Pediatric Exercise Science, 21, 520-532.

Babey, S. H., Hastert, T. A., Huang, W., \& Brown, E. R. (2009). Sociodemographic, family, and environmental factors associated with active commuting to school among US adolescents. Journal of Public Health Policy, 30(Suppl. 1), S203-S220.

Brodersen, N. H., Steptoe, A., Boniface, D. R., \& Wardle, J. (2007). Trends in physical activity and sedentary behaviour in adolescence: Ethnic and socioeconomic differences. British Journal of Sports Medicine, 4, 140-144.

Cohen, J. (1988). Statistical power analysis for the behavioral science (2nd ed.). Hillsdale, NJ: Erlbaum.

Collins, J. L., \& Fulton, J. (2015). Taking steps to a healthier nation: Increasing physical activity through walking. Journal of Physical Activity and Health, 12, S1-S2.

Daniels, S. R., Arnett, D. K., Eckel, R. H., Gidding, S. S., Hayman, L. L., Kumanyika, S., \& Williams, C. L. (2005). Overweight in children and adolescents: Pathophysiology, consequences, prevention, and treatment. Circulation, 111, 1999-2012.

Duncan, E. K., Duncan, J. S., \& Schofield, G. (2008). Pedometer-determined physical activity and active transport in girls. International Journal of Behavioral Nutrition and Physical Activity, 5, 2.

Faulkner, G. E. J., Buliung, R. N., Flora, P. K., \& Fusco, C. (2009). Active school transport, physical activity levels and body weight of children and youth: A systematic review. Preventive Medicine, 48, 3-8.

Frömel, K., Kudláček, M., Groffik, D., Chmelík, F., \& Jakubec, L. (2016). Differences in the intensity of physical activity during school days and weekends in Polish and Czech boys and girls. Annals of Agricultural and Environmental Medicine, 23, 357-360.

Frömel, K., Stelzer, J., Groffik, D., \& Ernest, J. (2008). Physical activity of children aged 6-8: The beginning of school attendance. Journal of Research in Childhood Education, 23, 29-40.

Frömel, K., Svozil, Z., Chmelík, F., Jakubec, L., \& Groffik, D. (2016). The role of physical education lessons 
and recesses in school lifestyle of adolescents. Journal of School Health, 86, 143-151.

Groffik, D., Sigmund, E., Frömel, K., Chmelík, F., \& Nováková Lokvencová, P. (2012). The contribution of school breaks to the all-day physical activity of 9- and 10 -year-old overweight and non-overweight children. International Journal of Public Health, 57, 711-718.

Hamřík, Z., Kalman, M., Bobáková, D., \& Sigmund, E. (2012). Sedavý životní styl a pasivní trávení volného času českých školáků [Sedentary lifestyle and passive leisure in Czech school-aged children]. Tělesná kultura, 35(1), 28-39.

Harrison, F., van Sluijs, E. M. F., Corder, K., \& Jones, A. (2016). School grounds and physical activity: Associations at secondary schools, and over the transition from primary to secondary schools. Health \& Place, 39, 34-42.

Haskell, W. L., Blair, S. N., \& Bouchard, C. (2007). An integrated view of physical activity, fitness, and health. In C. Bouchard, S. N. Blair, \& W. L. Haskell (Eds.), Physical Activity and Health (pp. 359-374). Champaign, IL: Human Kinetics.

Hood, N. E, Colabianchi, N., Terry-McElrath, Y. M., O'Malley, P. M., \& Johnston, L. D. (2014). Physical activity breaks and facilities in US secondary schools. Journal of School Health, 84, 697-705.

Horsch, A., Wobmann, M., Kriemler, S., Munsch, S., Borloz, S., Balz, A., ... Puder, J. J. (2015). Impact of physical activity on energy balance, food intake and choice in normal weight and obese children in the setting of acute social stress: A randomized controlled trial. BMC Pediatrics, 15, 12.

Howie, E. K., Campbell, A. C., \& Straker L. M. (2016). An active video game intervention does not improve physical activity and sedentary time of children at-risk for developmental coordination disorder: A crossover randomized trial. Child: Care, Health \& Development, 42, 253-260.

Jago, R., Anderson, C. B., Baranowski, T., \& Watson, K. (2005). Adolescent patterns of physical activity: Differences by gender, day, and time of day. American Journal of Preventive Medicine, 28, 447-452.

Kim, H. J., \& Lee, C. (2016). Does a more centrally located school promote walking to school? Spatial centrality in school-neighborhood settings. Journal of Physical Activity and Health, 13, 481-487.

Loucaides, C. A., Jago, R., \& Charalambous, I. (2009). Promoting physical activity during school break times: Piloting a simple, low cost intervention. Preventive Medicine, 48, 332-334.

Martin, S. L., Lee, S. M., \& Lowry, R. (2007). National prevalence and correlates of walking and bicycling to school. American Journal of Preventive Medicine, 33(2), 98-105.

Mei, H., Xiong, Y., Xie, S., Guo, B., Li, Y., Guo, B., \& Zhang, J. (2016). The impact of long-term school-based physical activity interventions on body mass index of primary school children - a meta-analysis of randomized controlled trials. BMC Public Health, 16, 205.

Meriwether, R. A., Lobelo, F., \& Pate, R. R. (2008). Clinical interventions to promote physical activity in youth. American Journal of Lifestyle Medicine, 2, 7-25.

Merom, D., Tudor-Locke, C., Bauman, A., \& Rissel, C. (2006). Active commuting to school among NSW primary school children: Implications for public health. Health \& Place, 12, 678-687.

Morton, K. L., Corder, K., Suhrcke, M., Harrison, F., Jones, A. P., van Sluijs, E. M. F., \& Atkin, A. J. (2016). School polices, programmes and facilities, and objectively measured sedentary time, LPA and MVPA: Associations in secondary school and over the transition from primary to secondary school. International Journal of Behavioral Nutrition and Physical Activity, 13, 1-11.

Nader, P. R., Bradley, R. H., Houts, R. M., McRitchie, S. L., \& O'Brien, M. (2008). Moderate to vigorous physical activity from ages 9 to 15 years. Journal of the American Medical Association, 300, 295-305.

Nettlefold, L., McKay, H. A., Warburton, D. E. R., McGuire, K. A., Bredin, S. S. D., \& Naylor, P. J. (2011). The challenge of low physical activity during the school day: At recess, lunch and in physical education. British Journal of Sports Medicine, 45, 813-819.

Nováková Lokvencová, P., Frömel, K., Chmelík, F., Groffik, D., \& Bebčáková, V. (2011). School and weekend physical activity of 15-16 year old Czech, Slovak and Polish adolescents. Acta Universitatis Palackianae Olomucensis. Gymnica, 41(3), 39-45.

Pastucha, D., Filipčíková, R., Bezdičková, M., Blažková, Z., \& Hyjánek, J. (2011). Pohyb v terapii a prevenci dětské obesity [Physical activity in the treatment and prevention of childhood obesity]. Prague, Czech Republic: Grada.

Pastucha, D., Talafa, V., Malinčíková, J., Hyjánek, J., Horáková, D., \& Beránková, J. (2010). Porovnání rizikových faktorů ve skupině obézních dětí a skupině atletů [Comparing risk factors in a group of obese children and group of athlets]. Tělesná kultura, 33(1), 98-107.

Pearson, N., Atkin, A. J., Biddle, S. J. H., Gorely, T., \& Edwardson, C. (2009). Patterns of adolescent physical activity and dietary behaviours. International Journal of Behavioral Nutrition and Physical Activity, 6, 45.

Rowlands, A. V., Pilgrim, E. L., \& Eston, R. G. (2008). Patterns of habitual activity across weekdays and weekend days in 9-11-year-old children. Preventive Medicine, 46, 317-324.

Schofield, G., Schofield, L., \& Mummery, K. (2005). Active transportation: An important part of adolescent physical activity. Youth Studies Australia, 24, 43-47.

Sheskin, D. J. (2007). Handbook of parametric and nonparametric statistical procedures (4th ed.). Boca Raton, FL: Chapman \& Hall/CRC.

Sigmund, E., Lokvencová, P., Sigmundová, D., Turoňová, K., \& Frömel, K. (2008). Vztahy mezi pohybovou aktivitou a inaktivitou rodičů a jejich 8-13letých dětí [The relation between physical activity and inactivity of parents and their children aged 8-13]. Tělesná kultura, 31(2), 89-101.

Sigmund, E., Sigmundová, D., \& El Ansari, W. (2009). Changes in physical activity in pre-schoolers and firstgrade children: Longitudinal study in the Czech Republic. Child: Care, Health \& Development, 35, 376-382.

Sigmundová, D., El Ansari, W., Sigmund, E., \& Frömel, K. (2011). Secular trends: A ten-year comparison of the amount and type of physical activity and inactivity of random samples of adolescents in the Czech Republic. BMC Public Health, 11, 731. 
Spallek, M., Tuner, C., Spinks, A., Bain, C., \& McClure, R. (2006). Walking to school: Distribution by age, sex and socio-economic status. Health Promotion Journal of Australia, 17, 134-138.

Svozil, Z., Frömel, K., Chmelík, F., Jakubec, L., Groffik, D., \& Šafár. M. (2015). Mental load and its compensation by physical activity in adolescents at secondary schools. Central European Journal of Public Health, 23(Suppl.), S44-S49.

Treuth, M. S., Catellier, D. J., Schmitz, K. H., Pate, R. R., Elder, J. P., McMurray, R. G., ... Webber, L. (2007). Weekend and weekday patterns of physical activity in overweight and normal-weight adolescent girls. Obesity, $15,1782-1788$.

Tudor-Locke, C., Craig, C. L., Beets, M. W., Belton, S., Cardon, G. M., Duncan, S., ... Blair, S. N. (2011). How many steps/day are enough? For children and adolescents.
International Journal of Behavioral Nutrition and Physical Activity, 8, 78 .

Tudor-Locke, C., McClain, J. J., Hart, T. L., Sisson, S. B., \& Washington, T. L. (2009). Expected values for pedometerdetermined physical activity in youth. Research Quarterly for Exercise and Sport, 80, 164-174.

Vašíčková, J., Pelclová, J., Frömel, K., Chmelík, F., \& Pelcl, M. (2008). Pilotní studie ročního režimu pohybové aktivity gymnaziálních studentek [Variability of year-round physical activity in high school girls: Pilot study]. Tělesná kultura, 31(2), 102-108.

Verstraete, S. J. M., Cardon, G. M., De Clerq, D. L. R., \& De Bourdeaudhuij, I. M. M. (2006). Increasing children's physical activity levels during recess periods in elementary schools: The effects of providing game equipment. European Journal of Public Health, 16, 415-419.

Ward, D. S., Saunders, R. P., \& Pate, R. R. (2007). Physical activity interventions in children and adolescents. Champaign, IL: Human Kinetics. 